\title{
Successful Use of a Highly Purified Plasma von Willebrand Factor Concentrate Containing Little FVIII for the Long-Term Prophylaxis of Severe (Type 3) von Willebrand's Disease
}

\author{
Tomas Simurda, $\mathrm{MD}^{1}$ Miroslava Dobrotova, $\mathrm{MD}, \mathrm{PhD}^{1} \quad$ Ingrid Skornova, MSc, $\mathrm{PhD}^{1}$ \\ Juraj Sokol, MD, $\mathrm{PhD}^{1}$ Peter Kubisz, MD, DSc ${ }^{1}$ Jan Stasko, MD, $\mathrm{PhD}^{1}$
}

\author{
1 National Centre of Hemostasis and Thrombosis, Department of \\ Hematology and Transfusiology, Comenius University in Bratislava, \\ Jessenius Faculty of Medicine in Martin, Martin, Slovakia \\ Semin Thromb Hemost 2017;43:639-641.
}

Address for correspondence Tomas Simurda, MD, National Centre of Hemostasis and Thrombosis, Department of Hematology and Transfusiology, Comenius University in Bratislava, Jessenius Faculty of Medicine in Martin, University Hospital, Kollarova Str. N. 2, Martin, 036 59, Slovakia (e-mail: tsimurda@orava.sk).
We read with great interest the article by Curnow et $\mathrm{al}^{1}{ }^{1}$ describing treatment of von Willebrand disease (VWD), as published in a recent issue of the journal, together with other interesting articles related to such disorders, as appearing in a recent issue of Seminars in Thrombosis $\mathcal{E}$ Hemostasis. We therefore wish to report our experience of the first successful use of a highly purified plasma von Willebrand factor (VWF) concentrate containing little FVIII in the long-term prophylaxis of severe vWD in Slovakia.

VWD is the most common inherited bleeding disorder caused by a quantitative and/or qualitative abnormality in the adhesive plasma protein $\mathrm{VWF}^{2}$ VWF represents a highmolecular-weight adhesive glycoprotein that plays an essential role in the primary hemostasis by promoting platelet adhesion to the subendothelium and platelet plug formation at the sites of vascular injury. VWD is classified into three major types: partial quantitative deficiency (type 1 ), qualitative deficiency (type 2), and complete quantitative deficiency (type 3). VWD type 2 is further divided into four variants (2A, $2 \mathrm{~B}, 2 \mathrm{~N}, 2 \mathrm{M}$ ), based on the characteristics of the dysfunctional VWF. ${ }^{1,3}$ Individuals presenting with clinical manifestations of VWD may have a mild, moderate, or severe bleeding tendency since childhood, usually proportional to the degree of the VWF deficiency/defect. ${ }^{4}$ There are two principle treatments of choice in VWD: desmopressin (DDAVP) and substitution therapy with blood products containing VWF (with/without factor VIII; FVIII). Other forms of treatment can be considered as adjunctive or alternative to those mentioned above. ${ }^{5}$

We present a male patient (now aged 34 years) with VWD type 3 (-Table $\mathbf{1}$ ). Our study was conducted in accordance with the Declaration of Helsinki. It was also approved by the institutional ethics committee on human research and informed consent was obtained. Early after birth, several spontaneous bleeding manifestations presented, which, over subsequent years, continued with many mucosal and joint bleeding episodes; these promoted the development of arthropathy. Substitution therapy was historically administered "on demand" during these events. From 1999, the then 17-year-old patient was subsequently treated with regular prophylactic administration of VWF/FVIII plasma-derived concentrates. Despite preventive administration, the patient continued to have recurrent mucosal bleeding and epistaxis, albeit with less frequent bleeding into joints. From December 2015, he was switched from a concentrate containing both VWF and FVIII to a highly purified plasma VWF concentrate containing little FVIII (Willfact; LFB Biomedicaments, France).

Levels of plasma VWF and FVIII in individuals with VWD can be regulated by the infusion of plasma-derived concentrates containing either VWF alone or VWF with FVIII. ${ }^{1}$ Available concentrates contain different amounts of VWF and FVIII, and the appropriate dosage should, therefore, be defined according to the specific product's characteristics. ${ }^{6}$ The primary symptoms of the severe form of VWD, comprising deficiency of both VWF and FVIII, may therefore comprise frequent hemophilia-like joint bleeds or recurrent spontaneous mucosal bleeding (e.g., epistaxis and gastrointestinal bleeding). Therefore, in patients with frequent bleeding, the treatment rationale is use of secondary long-term prophylaxis. ${ }^{6,7}$ Although patients with severe VWD produce FVIII, published online June 13, 2017
Issue Theme Editorial Compilation IV; Guest Editors: Emmanuel J. Favaloro, PhD, FFSc (RCPA), and Giuseppe Lippi, MD.
Copyright (c 2017 by Thieme Medical Publishers, Inc., 333 Seventh Avenue, New York, NY 10001, USA.

Tel: +1(212) 584-4662.
DOI https://doi.org/ 10.1055/s-0037-1603362. ISSN 0094-6176. 
Table 1 Laboratory tests of the patient with VWD type 3

\begin{tabular}{|l|l|l|}
\hline \multicolumn{2}{|l|}{} & Normal control \\
\hline Platelets $\left(\times 10^{-9} / \mathrm{L}\right)$ & 212 & $140-400$ \\
\hline Bleeding time (min) & 9 & $2-5$ \\
\hline PFA-100 Col/ADP $(\mathrm{s})$ & $>300$ & $62-100$ \\
\hline PFA-100 Col/Epi (s) & $>300$ & $82-150$ \\
\hline PT (s) & 11.7 & $10.4-12.6$ \\
\hline aPTT (s) & 46.4 & $22-32$ \\
\hline TT (s) & 11.9 & $15-22$ \\
\hline Fbg Clauss method (g.L-1) & $1.8-3.8$ \\
\hline VWF:RCo (IU/mL) & 2.0 & $0.5-1.4$ \\
\hline VWF:Ag (IU/mL) & 0.008 & $0.6-1.5$ \\
\hline FVIII:C (IU/mL) & 0.009 & $0.6-1.5$ \\
\hline $\begin{array}{l}\text { Ristocetin-induced } \\
\text { platelet aggregation (\%) }\end{array}$ & $60-90$ \\
\hline Multimers & 0.052 & \\
\hline
\end{tabular}

Abbreviations: ADP, adenosine diphosphate; VWF:Ag, von Willebrand factor antigen; aPTT, activated partial thromboplastin time; Epi, epinephrine; Fbg, fibrinogen; PFA, platelet function analyzer; PT, prothrombin time; TT, thrombin time; VDW, von Willebrand disease; VWF:RCo, von Willebrand factor ristocetin cofactor.
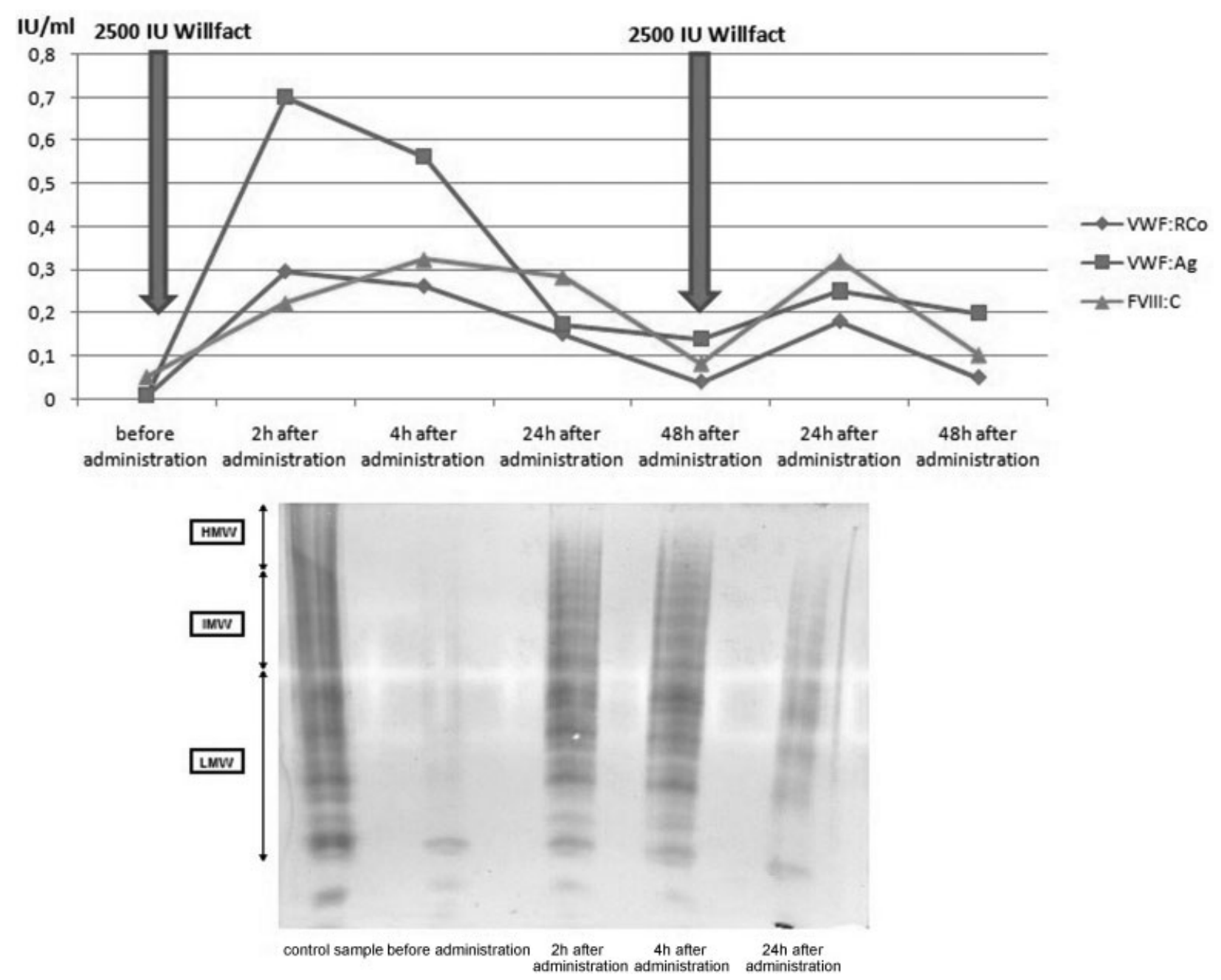

Fig. 1 The levels of von Willebrand factor ristocetin cofactor (VWF:RCo), von Willebrand factor antigen (VWF:Ag), factor VIII coagulation activity (FVIII:C), and VWF multimers analysis before and after administration of highly purified plasma VWF concentrate containing little FVIII. HMW, high-molecular-weight multimers; IMW, intermediate-molecular-weight multimers; LMW, low-molecular-weight multimers. 
the lack of VWF prevents stabilization of the FVIII and leads to its early degradation and an inherent plasma FVIII deficiency. However, continued dosing with a VWF/FVIII concentrate may lead to excess plasma levels of FVIII, because the concentrate contains FVIII and also provides VWF that in turn stabilizes the patient's endogenous FVIII. To avoid excessive replacement therapy-induced FVIII levels, a highly purified plasma VWF concentrate containing little FVIII has been developed, mainly for use in VWD. Insufficient or excessive circulating levels of FVIII achieved with replacement treatment can lead to inadequate hemostatic response or, alternatively, to a potential risk of thromboembolic events. ${ }^{8}$ Because of very low FVIII content, this particular VWF concentrate should be mainly used in patients unresponsive to DDAVP in situations such as surgical intervention and long-term prophylaxis; for surgical intervention, such a concentrate is suitable when patients have only a slightly reduced or normal FVIII levels.

Our patient received the intravenous bolus dose $32 \mathrm{IU} / \mathrm{kg}$ of highly purified plasma VWF concentrate containing little FVIII. Bolus dose increased the levels of VWF/FVIII after 2 hours to corresponding VWF:RCo $0.295 \mathrm{IU} / \mathrm{mL}$, VWF:Ag $0.701 \mathrm{IU} / \mathrm{mL}$, and FVIII:C $0.223 \mathrm{IU} / \mathrm{mL}$, respectively. The infused highly purified plasma VWF concentrate led to a rapid change of previously low levels of VWF/FVIII, to normalization of ristocetin-induced platelet aggregation (88\%), and detection of VWF multimers ( - Fig. 1). The VWF plasma peak was reached between 30 minutes and 2 hours after administration. The VWF half-life was between 8 and 14 hours, with a mean value of 12 hours. Normalization of FVIII level was progressive, varied, and was usually between 6 and 12 hours. This effect was sustained for 2 to 3 days. The highest levels of FVIII:C was $0.324-0.284 \mathrm{IU} / \mathrm{mL}$, VWF:RCo 0.261 to $0.151 \mathrm{IU} / \mathrm{mL}$, VWF:Ag 0.564 to $0.173 \mathrm{IU} / \mathrm{mL}$, and ristocetininduced platelet aggregation 86 to $88 \%$ during the first 24 hours after administration. These data are similar to those by Castaman et al. ${ }^{4}$ The concentrate was well tolerated and with no side effects.

Clinical experience with secondary prophylaxis in VWD has been rated as excellent or good in the large majority of case series, despite use of different schedules of administration. ${ }^{9,10}$

In our patient, reporting a personal history of serious hemorrhage, the prophylactic administration of VWF/FVIII concentrates has been changed to that of highly purified plasma VWF concentrate containing little FVIII $(2,500 \mathrm{IU} / \mathrm{kg}$ Willfact; patient weight $78 \mathrm{~kg}$, and calculated dose $32 \mathrm{IU} / \mathrm{kg}$ ) three times weekly from December 2015. Since then, he has noticed a significant reduction in the frequency and intensity of spontaneous bleeding. Patient's quality of life improved in comparison with prophylactic administration of VWF/FVIII concentrates. Nevertheless, we report the first prophylactic regimen of this concentrate used for patient with VWD in Slovakia.

In conclusion, secondary long-term prophylaxis with VWF concentrate containing little FVIII appears to reduce the frequency and intensity of bleeds in patients with VWD type 3. However, experience with long-term VWF concentrate prophylaxis is limited and the optimal dosage schedule has yet to be determined. Further prospective studies are necessary to investigate these issues.

\section{Acknowledgments}

This work has a general support by departmental chairs. We would like to thank the support of projects Vega $1 /$ 0168/16, Vega 1/0187/17, Grant Comenius University (UK/102/2017), Martin Center of Biomedicine (BioMed Martin, ITMS 26220220187) and Agency for the Support of Research and Development (APVV) 0222-11.

\section{References}

1 Curnow J, Pasalic L, Favaloro EJ. Treatment of von Willebrand disease. Semin Thromb Hemost 2016;42(02):133-146

2 Favaloro EJ. Towards personalised therapy for von Willebrand disease: a future role for recombinant products. Blood Transfus 2016;14(02):262-276

3 Favaloro EJ, Bonar R, Favaloro J, Koutts J. Diagnosis and management of von Willebrand disease in Australia. Semin Thromb Hemost 2011;37(05):542-554

4 Castaman G, Goodeve A, Eikenboom J; European Group on von Willebrand Disease. Principles of care for the diagnosis and treatment of von Willebrand disease. Haematologica 2013; 98(05):667-674

5 Favaloro EJ, Pasalic L, Curnow J. Monitoring therapy during treatment of von Willebrand disease. Semin Thromb Hemost 2017;43(03):338-354

6 Rocino A, Coppola A, Franchini M, et al; Italian Association of Haemophilia Centres (AICE) Working Party. Principles of treatment and update of recommendations for the management of haemophilia and congenital bleeding disorders in Italy. Blood Transfus 2014;12(04):575-598

7 Saccullo G, Makris M. Prophylaxis in von Willebrand disease: coming of age? Semin Thromb Hemost 2016;42(05):498-506

8 Mannucci PM, Kempton C, Millar C, et al; rVWF Ad Hoc Study Group. Pharmacokinetics and safety of a novel recombinant human von Willebrand factor manufactured with a plasma-free method: a prospective clinical trial. Blood 2013;122(05):648-657

9 Favaloro EJ, Bodó I, Israels SJ, Brown SA. von Willebrand disease and platelet disorders. Haemophilia 2014;20(Suppl 4):59-64

10 Holm E, Abshire TC, Bowen J, et al. Changes in bleeding patterns in von Willebrand disease after institution of long-term replacement therapy: results from the von Willebrand disease prophylaxis network. Blood Coagul Fibrinolysis 2015;26(04):383-388 